\title{
LITERATURA, HISTÓRIA E IMAGINÁRIO: A VIAGEM DE VASCO DA GAMA REVISITADA POR MÁRIO CLÁUDIO
}

\author{
Daniel Vecchio \\ danielvecchioalves@hotmail.com
}

Um velho no Inverno é a morte soprada, o tempo dorido, os fantasmas que a paciência esfarrapou. Poem-lhe aos pés a braseira, remexe as cinzas à procura de um rosto mais claro, aquieta-se nos reposteiros da sombra que o habita. Agasalha-se o velho no capote de castorina puído nos lugares do atrito dos gestos, salpicado pelos oceanos que imaginar. Está calado, e sente frio, não lhe perguntem da justiça dos homens que conheceu, nem da obra completa, nem do paraíso que pelo mundo andou buscando. (CLÂUDIO, 1998, p. 13).

\section{O VASCO DA GAMA DE ÁLVARO VELHO}

Para cercarmos as representações de Vasco da Gama (?-1524) na história e na literatura, seria produtivo termos em mãos relatos do próprio Capitão para elucidarmos alguns traços da sua memória e, por consequência, da sua identidade. Porém, não temos atualmente conhecimento de textos escritos por ele. Talvez nada escrevera até suas funções de Almirante a isso o terem obrigado, tais como algumas poucas cartas de requerimento ao Rei e ordens destinadas a sua tripulação. Não nos chegou qualquer relato de sua autoria sobre as três viagens que realizou para a Índia nos anos de 1497, 1502 e 1524. 
No tomo terceiro da Bibliotheca Lusitana (1752), Barbosa Machado (1682-1772) atribui a autoria de uma relação de viagem ao próprio Vasco da Gama, mas o bibliógrafo português não nos diz onde o documento se encontrava, indicando apenas por quem foi noticiado: "Vasco da Gama compôz a relação da viagem que fez á India em o anno de 1497. Desta obra e seu autor fazem menção António Nicoláo e António de Leão em suas obras, [...].” (MACHADO, 1752, p. 755). É lamentável que Barbosa Machado não nos indique a origem do documento, assim como os dois bibliógrafos por ele citados. Contudo, a afirmação de que o Gama teria escrito um relato de sua primeira viagem tornou-se muito vulgar.

Pode ser provável, também, que o manuscrito descoberto no Arquivo Municipal do Porto, em 1834, fosse anteriormente conhecido e noticiado aos bibliógrafos mencionados como escrito por Vasco da Gama. O professor de Matemática, Diogo Kopke (18o8-1844), e o professor de Botânica, Antônio da Costa Paiva (1806-1879), ambos da Academia Politécnica do Porto, descobriram, na gaveta número 804 dos empoeirados arquivos da Biblioteca Municipal dessa cidade, um manuscrito que imediatamente perceberam ter sido redigido no século XV. Sabe-se que tal manuscrito fora trazido, poucos anos antes, da biblioteca do antigo Mosteiro de Santa Cruz de Coimbra e nada mais.

Depois de estudarem por quatro anos a fio esse manuscrito, Diogo Kopke e Costa Paiva, convencidos de sua autenticidade, decidiram publicá-lo, às próprias custas, em fevereiro de 1838. Com o título Roteiro da Viagem que em Descobrimento da Índia pelo Cabo da Boa Esperança fez Dom Vasco da Gama em 1497, é publicada a obra que marca o único registro sobre a primeira viagem de Vasco da Gama às Índias Orientais. Os investigadores portuenses, no entanto, atribuíram sua autoria não ao Capitão como era mais esperado, mas ao marinheiro chamado Álvaro Velho'. A identificação do autor do manuscrito partiu da hipótese de que, na crônica de Fernão Lopes de Castanheda (1500-1559), História do Descobrimento e Conquista da Índia pelos Portugueses, o autor do

${ }^{1}$ Não existem informações acerca do nascimento ou morte de Álvaro Velho (1450?1500?) e não sabemos das suas funções a bordo. Encontramos, no entanto, duas únicas obras que lhe fazem menção: O Manuscrito Valentim Fernandes (Academia Portuguesa de História, 1940), no qual é mencionado o nome Álvaro Velho do Barreiro como a fonte viva para que o cronista realizasse a sua descrição das costas da Guiné; e a História dos Descobrimentos e Conquistas da Índia pelos Portugueses (1553) de Fernão Lopes de Castanheda, quando participa da primeira embaixada de Gama ao Samorim, rei de Calicute. Nessa pesquisa, utilizaremos a primeira versão de 1838 organizada por D. Kopke e Costa Paiva. 
relato fora nomeado como parte da escolta com a qual Vasco da Gama desembarcara para realizar a primeira embaixada ao Samorim de Calicute.

Por descrever tal episódio diplomático, supuseram tais investigadores que o autor do relato só poderia ser um dos treze marinheiros participantes da embaixada apontados por esse cronista. Kopke e Paiva utilizaram-se de argumentos sólidos e engenhosos para eliminá-los um a um, restando, por fim, apenas Álvaro Velho. Trata-se de um dos principais documentos para o estudo da viagem de Vasco da Gama, escrito por uma testemunha presencial dos fatos que relata. Nos anos seguintes, o manuscrito ganharia novas edições. Em 1861, o mesmo Costa Paiva financiou uma reedição da obra, que dessa vez teve introdução e notas feitas pelo historiador Alexandre Herculano (1810-1877).

Seguida por muitas outras edições, constatamos que o texto de Álvaro Velho, desde sua primeira edição em 1838 até as décadas finais do século seguinte, é classificado como "roteiro" ou "diário". Somente a partir da década de 1980, com os historiadores Luís de Albuquerque e João Rocha Pinto, é que o termo "relação" é publicado como título, surgindo como uma tentativa de revisão estrutural e classificativa de sua narrativa ${ }^{2}$.

A vantagem de utilizarmos o termo "relação" para reconhecê-lo está em compreendermos melhor como se caracteriza sua composição textual, que se difere de um roteiro ou de um diário3. Em uma relação, segundo as palavras de João Rocha Pinto, “os acontecimentos de monta comandam a escrita e não o tempo, como aconteceria se fosse de fato um diário de bordo." (PINTO, 1989, p. 121).

Esta é, aliás, a mais importante característica narrativa que deve ser destacada de uma relação de viagem, ou seja, uma narração que se deixa tomar por completo pela descrição do espaço empírico, cobrindo os contatos com terras, ilhas e pontos costeiros que surgem ao longo da viagem, como vemos no excerto: "Estando nesta angra de Sam Bras tomando agoa huũa quarta feira posemos huũa cruz e huũ padram em a

${ }^{2}$ No que se remete às relações de viagem, vale ressaltar os estudos do professor João Rocha Pinto intitulado A Viagem, Memória e Espaço - A Literatura Portuguesa de Viagens: os primitivos relatos de viagem ao Índico (1497-1550). In: Revista de História Economica e Social. Lisboa, Livraria Sá da Costa Editora, 1989, n.ํ11-12.

${ }^{3} \mathrm{Na}$ famosa tipologia da Literatura Portuguesa de Viagens de Joaquim Barradas de Carvalho, a relação ainda não era um gênero reconhecido, sendo suas fontes agrupadas no gênero diário de bordo. Ver $O$ renascimento português: em busca de sua especificidade. Lisboa: INCM, 1980. 
dita amgra de Sam Bras, a qual cruz fezemos de huũa mezena e era mujto alta." (VELHO, 1838, p. 166).

Na relação de Álvaro Velho, como em todo relato produzido em sua época, o que é visto ganha estatuto de existência. Porém, conforme diz Eni Orlandi, cabe salientar que "ver, tornar visível, é uma forma de apropriação. O que o olhar abarca é o que se torna ao alcance das mãos. O visível (o descoberto) é o preâmbulo do legível: conhecido, relatado, codificado. Primeiro passo para que se assente a sua posse. A submissão às letras começa e termina no olhar" (ORLANDI, 2008, p. 17). Na realidade, pode-se dizer que, no geral, o discurso das descobertas se organiza em função de dar notícias do que vê.

No entanto, é preciso ressaltar, antes de tudo, que há nessa composição narrativa, na verdade, um jogo de observações e ocultações que deve ser percebido, pois uma narrativa de viagem está ligada a práticas e não somente ao sentido da visão, por isso ela também se organiza tendo como parâmetro as relações de poder pelas quais as visões são descritas. Dessa forma, com uma estratégia narrativa construída em função do que o narrador simplesmente quer ver, não encontramos um perfil ou retrato efetivo de Vasco da Gama, diríamos que não estava na natureza do gênero fazê-lo, mas "olhemos o ponto de vista, o lugar de articulação do espaço social com o espaço textual, donde nasce a escrita de Álvaro Velho. [...], existe na descritiva uma tentativa de silenciar esta dimensão através duma impessoal objetividade criadora de fotografia sem fotógrafos." (BARRETO, 1983, p. 133).

O que apenas podemos apontar de saliente no perfil de Vasco da Gama, na Relação de Álvaro Velho, é o seu retrato moral de Capitão-mor com relação aos atos de grande prudência e virtude, demonstrando rígido cumprimento e obediência do regimento para uma segura navegação, e à execução de embaixadas que lhe ordenou fazer seu Rei: "E o capitam lhe dise como elle era embaixador de huũ Rey de Portugall o quall era senhor de mujta terra e era mujto rrico de todas as cousas majs que nenhũ Rey daquellas partes [...]" (VELHO, 1838, p. 178).

Além disso, devemos perceber que essa estratégia de escrita da relação em questão corrobora para que as emoções individuais do observador que relatou tal empresa não fossem alvo de registros. Parece que, de modo geral, a viagem nem sequer sensibilizou seu narrador. Poderíamos concluir que o seu dispêndio de meses em alto mar foi relativamente suportável e sem grandes problemas. Entretanto, é preciso dizer que, ainda assim, "a 
arquitetura semântica de Álvaro Velho não se apresenta como construção neutra, operatória e racionalizante, mas como mensagem registadora da intuição [...]." (BARRETO, 1983, p. 129).

Naquela época, sabemos que o grande mar ainda era visto como um dos caminhos mais hostis que o homem podia enfrentar no globo. Na superfície oceânica, o medo parecia reinar onipresente, e essa viagem marítima não poderia deixar de ser de tal maneira conturbada, tanto que é de se estranhar que o narrador da Relação nada tenha registrado diretamente dos seus medos. No entanto, descrever somente os espaços observados foi uma estratégia que não evitou que o texto de Âlvaro Velho falhasse na pretensão exclusiva à veracidade do real representado. Podemos perceber, na leitura dessa relação de viagem, uma pequena parte das emoções do narrador que embaralhou a consistência verídica de suas descrições, fazendo-o confundir os espaços, as pessoas e os objetos observados.

Atenta-se o leitor da Relação que há momentos recorrentes em que o narrador afirma ver "xhristãos", esta afirmação aparece na descrição de Moçambique à costa do Malabar. Uma das principais cenas narradas no texto focaliza justamente o momento no qual desembarca o Capitão Vasco da Gama com sua embaixada na atual cidade indiana de Kozhikode, e em que o narrador começa a adquirir provas sucessivas de que aquela terra pertence aos cristãos, observando suas igrejas, suas imagens de santos e de outras entidades divinas do cristianismo:

\begin{abstract}
Aquy nos levaram a hua grande Igreja em a quall estavam estas cousas seguintes. Primeiramente ho corpo da Igreja He da grandura duu mosteiro toda lavrada de quantaria, telhada de ladrilho, e tinha a porta principall hu padram darame daltura de hu masto e em cima deste padram esta hua ave que parece gallo, e outro padram daltura de huu omem e mujto groso. E em meo do corpo da Igreja esta huu corucheo todo de quanto, e tinha hua porta quanto huu home cabia, e hua escada de pedra prque sobiam há esta porta, e dentro estava huua ymagem pequena a quall elles diziam que era nosa Senhora, [...]. E outros mujtos santos estavam pintados pellas parredes da Igreja os quaes tinham diademmoas, e a sua pimtura hera em diversa maneira porque os dentes eram tam grandes que sayam da boca hua polegada, e cada santo tinha quatro e çinquo braços, e abaixo desta Igreja estava hu gram tanque lavrado de quantaria asy como outros mujtos que pello camjnho tínhamos visto. [...]. E quanto majs nos chegavamos pera os paços onde ElRey estava tamto majs jemte rrecrecia. (VELHO, 1838, p. 176).
\end{abstract}

O choque cultural não acontece casualmente, ele é produzido. Exemplo disso é Álvaro Velho que, como visto na citação anterior, julgando 
estarem os portugueses rodeados de cristãos convertidos por São Tomé4, tem a ilusão de, ao entrar em um templo hindu, se encontrar em uma igreja. Sabemos que os portugueses daquela época ainda não conheciam os hindus, acabando por confundi-los com cristãos. Nesse momento descritivo, as estranhezas foram apropriadas, ou seja, completamente inscritas nas instituições político-religiosas dos portugueses.

Isso pode ser observado pelo fato de que é ressaltada nesse excerto a crença de Álvaro Velho nas lendas cristãs ultraterrestres, que divulgavam a existência de reinos cristãos em terras desconhecidas e distantes, como o reino do Preste João e outros reinos ainda não vistos. Podemos interpretar, com isso, que a visão, sentido tão importante para os séculos XV e XVI, não proporcionou, e nem proporciona, uma ferramenta cognitiva suficiente para totalizar a representação ou o significado de algo ou alguém.

Denominando os hindus de cristãos, a Relação de Álvaro Velho testemunha a dificuldade do português da época em observar os espaços, aceitando as diferenças culturais, sejam elas no campo científico, religioso ou político. O navegador português compreendia os indianos apenas levando em conta seu horizonte de expectativa imaginário: "Tudo indica Gama ter zarpado de Portugal partindo do princípio de que a Índia era sobretudo habitada por cristãos, com uma minoria muçulmana [...]." (DISNEY, 2010. p. 297-298). As outras duas relações portuguesas provenientes das outras viagens de Vasco da Gama à Índia, a Relação Anônima e a Relação de Tomé Lopes ${ }^{5}$, sem confundir hindus com cristãos, ainda repetem tais circunstâncias lendárias, ao evocarem, por exemplo, a existência do reino de Preste João em diversos momentos.

4 É frequente a referência das fontes às cristandades orientais na figura do apóstolo São Tomé que estaria na origem da conversão dessas comunidades. "Segundo a tradição lendária, baseada no apógrafo do século III Actos de Tomé, a Índia ter-lhe-ia sido atribuída." (FONSECA, 1998, p. 253).

${ }^{5}$ A Relação Anônima da segunda viagem gâmica só foi revelada no século XX pela bibliotecária Christine von Rohr, em 1929, em um capítulo que compõe a obra Beitragen Zur Historischen Geographie, publicada em Viena. "Atualmente o texto está contido no códice número 6948 e faz parte do acervo da National Staatsbibliothek de Viena. Foi editado pela primeira e única vez pela mesma Christine von Rohr, num livrinho intitulado Neue Quellen zur Zweiten Indienfahrt Vasco da Gamas, datado de Leipzig, 1939, sob a chancela de K. F. Koehler Verlag." (PINTO, 1985, p. 141). A outra relação dessa mesma viagem foi escrita por Tomé Lopes, marinheiro da nau comandada por Estevão da Gama, filho do Almirante. O texto pode ser encontrado em A Navegação às Índias Orientais. In: CRUZ, António. O Porto nas navegações e na expansão. 2. ed edição. Lisboa: Instituto de Cultura e Língua Portuguesa, 1983. 
A partir dessas e outras fontes, começa a nascer, no século XVI, uma nova idade no conhecimento europeu acerca das Índias. Cresce a quantidade e a qualidade das informações indiretas sobre as viagens ibéricas através dos tratados de história e das crônicas. Tal produção implicará uma incipiente recolha sistematizada e tratada como informação, de maior especialização e setorização dos saberes, sobre as terras desconhecidas do Ocidente e do Oriente.

A primeira historiografia acerca das viagens dos descobrimentos portugueses, composta por cronistas e historiadores como Rui de Pina, Garcia de Resende, Jerônimo Osório, Damião de Góis, Fernão Lopes de Castanheda, Gaspar Correia e João de Barros, surge como um discurso ressonante da mesma grandeza e virtuosidade dos navegadores representados nas relações de viagem, cuja documentação lhes serviu de base de investigação. Não há dúvidas de que com essa primeira historiografia dos descobrimentos, fora dado maior realce à elaboração extremamente generalizante para explicar o processo da expansão ultramarina portuguesa, partindo os cronistas de observações de ordem religiosa, política, econômica, social e técnica.

Tal historiografia baseava-se na noção de descobrir e propagar, duas práticas que sustentarão a ideia de expansão proliferada na Península Ibérica nos séculos XV e XVI. Os descobrimentos e a expansão ocupavam, já nessa época, um lugar muito importante no quadro evolutivo que estabeleciam para o desenvolvimento da humanidade, inserindo-os no movimento cultural e científico do Renascimento. Por isso, confrontando a Relação de Álvaro Velho com as crônicas dos descobrimentos, é relativamente mais fácil apontarmos as semelhanças por meio dessa perspectiva idealista da expansão ultramarina, do que apontar as modificações de pequenos detalhes que pouco alteram o conteúdo representativo das viagens relatadas.

Conforme acentuou Hernâni Cidade (1887-1975), "todos os escritores dos Descobrimentos procuram justificar as violências inevitáveis nos costumes do tempo com objetivos religiosos que transcendiam os egoísmos desencadeados" (CIDADE, 1963, p. 91). Nesse sentido, seja nas relações de viagem ou nas crônicas, evidencia-se a atribuição, à nação portuguesa, de um divino mandado de conquista do mundo para Deus, ocultando ou justificando com isso as crueldades de um Vasco da Gama em Calecute, ou de um Afonso de Albuquerque no cerco de Ormuz. 
Quanto ao pesquisador que remexer as relações de viagem e as crônicas dos séculos XV e XVI na busca por informações biográficas mais completas de Vasco da Gama, além de uma apresentação superficial sobre suas empresas marítimas, encontrará um provocante silêncio que oculta as desavenças do navegador com o rei D. Manuel e outros chefes, bem como as conturbações da viagem e os traumas da tripulação.

Com essa historiografia incipiente sobre os navegadores e suas viagens de descobrimento, conclui-se que "a forma como uma sociedade imagina o seu passado é um produto de complexas estruturas antropológicas de todo um imaginário sociocultural e um interessante objeto de falsa consciência, [...]." (BARRETO, 1983, pp. 9-10). Sendo assim, observamos que os "lugares da memória" são, antes de tudo, restos, uma "forma extrema onde subsiste uma consciência comemorativa numa história que a chama, porque ela a ignora. Somente a desritualização de nosso mundo faz aparecer tal noção estrutural." (NORA, 1993, pp. 12-13).

Partindo desse processo crítico de "desritualização", concluímos que os escribas e cronistas do reino lusíada reproduziram um perfil oficial de Vasco da Gama, assegurando sua representação com base no valor da Areté que é atribuída ao indivíduo que se destacou em coragem e honra no seio de seu grupo, através de feitos extraordinários obtidos em situações de extrema dificuldade. Para melhor assimilar essa perspectiva crítica, vale ressaltar aqui as palavras de Vitorino Magalhães Godinho (1918-2011) ao dizer que "a história dos descobrimentos e da expansão crescera ao serviço de reivindicações nacionais e na obsessão das prioridades no descobrir e ocupar" (GODINHO, 2008, p. 25).

Em seu clássico A Expansão Quatrocentista Portuguesa, obra censurada pela comissão organizadora das Comemorações Henriquinas em 196o, torna-se muito evidente a sua ideia de que só uma sociologia histórica das comemorações dos descobrimentos portugueses é capaz de nos elucidar o que representou de fato tal evento para a coletividade lusitana. É nessa perspectiva que se torna necessária a abordagem das obras envolvidas com a representação da pioneira viagem de Vasco da Gama, a fim de que as construções desse episódio sejam analisadas adequadamente, com base no foco adotado por esta investigação. 


\section{LIBERTANDO-SE DAS AMARRAS DA ÉPICA GÂMICA}

Protagonista da viagem de 1497-1499, Vasco da Gama é o personagem por excelência de um dos acontecimentos de referência da história de Portugal e do mundo, sendo determinante no processo das navegações oceânicas, na história do Ocidente e nas suas relações com o Oriente, em uma conjuntura que caracteriza a transição do mundo medieval para o moderno. Essas representações foram decisivas na modelação da mentalidade nacional portuguesa, contribuindo para a construção de um deslumbramento patriótico:

O orgulho do feito nacional, com a visão épica das navegações e das conquistas, predominou, durante gerações e gerações, sobre todos os outros sentimentos desencadeados pela Expansão na alma dos portugueses, [...]. Ficou a constituir, desde o dealbar do século XVI, um ingrediente fundamental da maneira de nos concebermos na história ou de reagirmos perante a vida. [...]. Esta maneira de ver a nossa ação além dos mares penetrou profundamente nos espíritos. (DIAS, 1982, p. 15).

Em grande parte da literatura e da cultura portuguesa, a partir do século XVI, sobressai principalmente essa tendência à exaltação mítica dos descobrimentos. A representação de Vasco da Gama, portanto, entrelaça-se com o imaginário épico, do qual as relações e as crônicas não conseguem se desvencilhar.

Problematizando essa mitificação da cultura portuguesa, com base nos heróis navegantes do passado, o Vasco da Gama da Peregrinação de Barnabé das Índias, do romancista contemporâneo Mário Cláudio ${ }^{6}$, livro lançado no período das celebrações do quinto centenário da primeira viagem às Índias, em 1997, apesar de ter a glória de ter cumprido o caminho marítimo planejado, sente-se esquecido e vive longe da corte.

Nesse romance, evidenciam-se informações denegridoras acerca da família Gama, que funcionam como dispositivos antiépicos de

${ }^{6}$ Segundo o Dicionário de Literatura Portuguesa de Álvaro Manuel Machado, Mário Cláudio é pseudônimo literário de Rui Manuel Pinto Barbot Costa. De origem irlandesa por parte de avós, nasceu no Porto em 1941. Ficcionista, poeta e ensaísta, trata-se de um intelectual dotado de uma sólida carreira, com destaque para sua formação em Direito pela Universidade de Coimbra, onde se diplomou também como bibliotecário-arquivista. Destaca-se também sua atividade docente na Escola Superior de Jornalismo do Porto. Ligada diretamente a essa formação, em nossa leitura, sua obra literária apresenta uma faceta de investigador e de bibliófilo que, encontrando na literatura a continuidade da sua atividade profissional, passa a inscrever investigativamente cada um dos seus livros. 
representação, por meio dos quais reelabora Mário Cláudio todo o cenário interior e exterior do evento histórico em questão. A representação no plano exterior ocorre muito no primeiro capítulo "As Neves", em que se apresentam mais dados biográficos do Gama e é quando a narrativa opta por começar a informar alguns dados históricos que envolvem cenários políticos e familiares, cada vez mais dramáticos.

A sua ficção parte de muitas das hipóteses e especulações históricas negativas na vida dos Gama, hipóteses que já tinham sido levantadas anteriormente por alguns historiadores 7 . Em resumo, sua narração, além de representar de forma intensa os surtos imaginários que ainda vamos analisar, é uma narrativa marcada também por cenários que mostram os acontecimentos exteriores da vida de Vasco da Gama, destacando os episódios que demonstram o enfraquecimento político e moral de sua família.

O romance segue nessa esteira de hipóteses, expondo as desavenças da família com os reis e outros chefes do reino português. Dentre elas, deparamo-nos com o anúncio da carta de expulsão do Gama de Sines, sua cidade natal, em documento assinado pelo rei D. Manuel I e por D. Jorge, chefe da Ordem de Santiago. Temos no romance, também, a exposição da carta de Vasco da Gama a esse mesmo rei, em que, previamente, avisava-o de sua dramática retirada do reino, por ainda não ter sido agraciado com o título de Conde - há anos requisitado.

Com base em estudos, o romance mostra que essas dificuldades políticas são provenientes, na verdade, de conflitos muito mais antigos do que o ano de 1497, quando partia Vasco pela primeira vez às Índias. Mário Cláudio constrói a personalidade desse navegador partindo de hipotéticas marcas traumáticas efetuadas no decorrer das primeiras décadas de sua vida. Trata-se do período do reinado de D. João II (1455-1495), de quem Vasco tem vaga lembrança através de um passado violento representado pelo "seu vulto todo sujo de sangue, desdobrando-se-lhe à frente o tapete de cadáveres e de prisioneiros" (CLÁUDIO, 1998, p. 29).

D. João II teria deixado afetiva e financeiramente a família Gama em estado precário. Teria esse Rei confiscado todos os bens e bonificações do cavaleiro assassinado Estevão da Gama (1430-1497?), pai do navegador, por ter participado esse cavaleiro de um grupo de conspiradores contra o seu

7 Ver os estudos de Visconde Sanches de Baena e Teixeira de Aragão, cujas referências se encontram na bibliografia. 
reinado ${ }^{8}$. Deixou aos seus filhos somente "os benefícios procedentes das saboarias de Estremoz, de Sousel e de Fronteira”. Esse fato é interpretado pelo narrador do romance como um "consumado sarcasmo", pois, contra a conspiração de Estevão, o rei recomendava indiretamente à família "lavarem-se e voltarem a lavar-se, a fim de se purificar da nódoa que lhes conspurcava o nome" (CLÁUDIO, 1998, pp. 29-30).

Essa versão corrobora para a defesa de que Vasco da Gama teria naturalmente tentado a todo custo reparar os danos causados a sua família, que ficou sem os bens pertencentes ao seu pai, principalmente o governo de Sines. A coragem de enfrentar a perigosa e mítica empresa marítima de 1497, empresa essa que realizou por três vezes, não nos deixa mentir sobre essa euforia. Fixada a ideia de ascensão, tomar a frente de qualquer empresa misteriosa e grandiosa poderia ser a única chance de Vasco marcar novamente o nome dos Gama nas gestas de sua nação.

Nesse contexto político é que se acentua a coerente relação de Vasco com todo o tipo de mito e lenda sobre as partes orientais, cuja comprovação tornaria mais do que grandioso e heróico seu feito marítimo. Contudo, no romance, os imaginários míticos são caracterizados por um tom doentio e alucinador, pois Vasco regressa sem devassar um único mistério, "abrindo apenas com a proa da sua caravella um rasgão no véu de sombras imperscrutáveis na apparencia que velava a toda cobiça a India de luz e de ouro." (MONTEIRO, 1898, p. 499).

Portanto, as relações dos elementos sociopolíticos com a própria psicologia do navegador são bastante aproveitadas por Mário Cláudio para alcançar, em sua obra romanesca, um efeito oposto daquele fornecido pela tradição, ou seja, contrário à dimensão de magnitude dos navegantes registrados nos relatos e nas crônicas. Com isso, veremos que Mário Cláudio não apenas investirá nas condutas imaginárias que se desviam da mentalidade comum, sobrepondo o mental aos outros componentes da sociedade por ele retratada. O tom dominante de sua intervenção histórica

${ }^{8}$ A participação de Estevão no grupo de conspiradores é anteriormente mencionada por alguns investigadores da Sociedade de Geografia de Lisboa. Para analisar esse episódio, voltemos ao final do século XIX, a fim de acompanhar brevemente o momento em que, pela primeira vez, levantavam-se tais hipóteses históricas por parte dos liberais mais radicais vinculados a tal Sociedade. O Visconde de Sanches de Baena, cuja obra O Descobridor do Brazil de 1897, valendo-se de sua erudição genealógica e dando seguimento em aprofundar a construção da imagem denegrida dos Gama, analisa indícios que modificaram, em especial a forma apaziguadora em que a tradição cronística atém-se sobre o desfecho da vida de Estevão da Gama, chefe dessa família. 
é coerente com o que diz Roger Chartier acerca das representações históricas, "cujo foco está inicialmente nas práticas sociais para, consequentemente, obter as representações integradas a essas práticas em que a ideia de imaginário não deixa de se sobrepor" (CHARTIER, 1990). Averiguaremos que o conteúdo histórico do romance é constituído por muito mais do que enunciados ou crenças aparentemente estranhos, bizarros, paradoxais, incoerentes ou carregados de contradições, mas daquilo que se poderia chamar "o acreditável disponível de uma época. [...]. A noção de mentalidade é então devolvida ao seu estatuto de objeto novo do discurso historiador no espaço deixado a descoberto pelo econômico, o social e o político. É um explicandum, não um princípio preguiçoso de explicação." (RICOEUR, 2008, p. 209).

O pretenso não-dito e implícito que o conceito de mentalidade pressupõe desdobra-se em uma complexa rede de aquisições graduais e circunstanciadas das questões sociopolíticas vividas pela família de Vasco da Gama. De tais alíneas mencionadas, apresenta-se uma estrutura miscigenada de uma contraepopeia em prosa, que provoca representações sucessivas de um perfil negativo dos Reis e as complexas relações da realeza com a família desse famoso navegador tão exaltado por Camões.

Dialogando com esses cenários, temos, principalmente nos cinco primeiros capítulos do livro, um dispositivo antiépico resultante da representação de um imaginário medieval fantástico pelo qual estão enfeitiçados os personagens. Como o próprio título do romance anuncia, estamos lidando, sobretudo, com uma peregrinação, o que implica consequentemente uma relação com toda a carga imaginária acumulada por séculos e séculos de romaria.

O romancista nos mostra que Vasco da Gama e os outros marinheiros não tinham cultura suficiente para combater os fantasmas e os monstros de Ptolomeu, Plínio, Pompónio Mela, Estrabão e tantos outros que escreveram seus Imago Mundi ${ }^{9}$ e seus mapas cartográficos considerando a existência de lugares e seres fantásticos. Não sossega o Capitão-mor de contemplar monstros nas longas tempestades durante a viagem, tendo a sensação convicta de que o forte balanço da nau é causado pelo movimento

9 Imago Mundi é o título latino de vários livros antigos e medievais, incluindo a mais famosa cosmografia escrita em 1410 pelo teólogo francês Pierre d'Ailly (1351-1420). Imago é uma imagem ou representação no significado latino. Assim, o título é traduzido por Imagem do Mundo, sendo comum nessas obras a apresentação de listas e mais listas de híbridos pavorosos que preenchiam o orbe, segundo a mentalidade de tradição medieval. 
de um deles nas profundezas do mar. Nesse romance, a hidra de sete cabeças é símbolo da ansiedade descontrolada de descobrir, triunfo dos espaços imaginados, uma busca dentre os "intervalos do subterrâneo de si mesmo que é onde o monstro se alojava, e que a um sinal do exterior, raio do luar ou queda da temperatura, haveria de se enfurecer e de se avolumar, a fim de ir catalisando a devastação deste Mundo." (CLÁUDIO, 1998, p. 39).

Há, nesse ponto imaginário ficcional, ademais, certa coerência histórica. Veremos que não se trata de uma invenção gratuita do escritor que muito bem pesquisou sobre a mentalidade desse e de outros navegadores da época. Nas investigações históricas que inevitavelmente realizou para a construção do romance, informou-se Mário Cláudio de que nem sempre a viagem expansionista foi um fator transformador da cognição humana. Ilhas e reinos imaginários, hidras, gigantes e muitas outras imagens insólitas, que eram consideradas verossímeis e habitavam a mentalidade popular europeia, eram expressas cautelosamente em diversos relatos ultramarinos que descreviam os mundos até então pouco ou nada conhecidos.

Somente com os estudos da história dos imaginários dos pioneiros John Huizinga, Jacques Le Goff, Georges Duby, Jean Delumeau, Claude Kappler e outros, é que foi plenamente reconhecida uma forte presença de uma mentalidade maravilhosa em pleno Renascimento Cultural e nas eras subsequentes. Os estudos desses aspectos imaginários através da história dos descobrimentos ultramarinos não deixam dúvidas.

Com essa nova historiografia, desponta uma gama de estudos que atentam para o desdobramento de um extenso conjunto de imaginários produzido pelos homens. Essa escola historiográfica, considerada como arte da terceira geração dos Annales ${ }^{10}$, foi a primeira a se interessar por determinados temas não convencionais, por objetos historiográficos, até então desconsiderados como fonte histórica, desbravando certos domínios da história que a grande maioria dos pesquisadores ainda não havia pensado em investigar.

${ }^{10} \mathrm{O}$ programa da Nova História Cultural, escola da terceira e quarta gerações do grupo francês Annales, foi estabelecido a partir de bases teóricas que consideram as relações complexas entre a vida real dos homens e as representações que eles produzem de si mesmos. É uma história preocupada, antes de tudo, com uma antropologia que visa evitar dialéticas, reducionismos e mecanicismos na interpretação da realidade histórica, e, para isso, considera as motivações mentais e as tendências historiográficas como elementos fundamentais para uma abordagem analítica e densa sobre o passado. 
É mais do que necessário utilizar essearcabouço teórico-metodológico para nos guiarmos para além das convenções e dos silêncios do discurso hegemônico da Relação de Álvaro Velho, investigando os ocultos contextos simbólicos e imaginários em torno da primeira viagem histórica de Vasco da Gama. Assim, torna-se muito considerável a hipótese de que tal base teórica da historiografia cultural tenha contribuído para que Mário Cláudio encontrasse rica matéria para a representação dos aspectos subjetivos da viagem em questão.

Nesse ponto, o romancista acaba por se comprometer com uma representação além do visível e do aparente dos fatos, com aquilo que constitui a essência mesma de todos os acontecimentos: a manifestação imaginária de um grupo. A representação desses imaginários no romance funciona a partir de um mecanismo alegórico muito próximo da tradição narrativa proveniente das viagens e das peregrinações anteriores, como os famosos relatos produzidos pelos viajantes franciscanos e pelos viajantes humanistas ao longo da passagem da Idade Média para o Renascimento ${ }^{11}$.

Ponderando e sistematizando as representações narrativas do imaginário maravilhoso desde a antiguidade até os tempos modernos, surge a conhecida sistematização dada por Todorov a essas representações, que estariam, segundo ele, associadas ao gênero do fantástico. Contudo, nessa pesquisa, basear-nos-emos na ideia de que o maravilhoso assemelha-se a uma rede que abarca dinamicamente variados modos de construção, ou seja, o fantástico não será considerado pela perspectiva de gênero, mas pela perspectiva das representações e das práticas associadas ao imaginário, de acordo com Filipe Furtado, Irène Bessière e Remo Cesarani ${ }^{12}$.

A estudiosa francesa Irène Bessière, por exemplo, afirma que a manifestação fantástica não pode ser definida como uma categoria ou gênero, porque ela implica uma lógica narrativa e temática variável de acordo com as experiências no tempo e no espaço. Bessière ainda assinala que a narrativa fantástica não se define apenas pelo inverossímil ou pelo

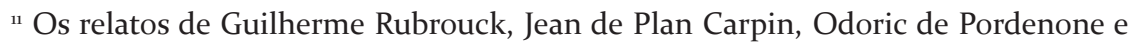
Marco Polo apresentavam, no geral, uma mescla da observação pessoal e da intercalação fabulosa que engrossava as páginas dos manuscritos. Todavia, é preciso dizer que a conjunção do testemunho da experiência e do lendário, que frequentemente contamina esse tipo de texto, obedece a causas mais complexas que a ingenuidade de uma época ou a submissão de uma tradição literária estabelecida.

${ }^{12}$ Ver referências completas na bibliografia. 
insólito, como é categorizado geralmente, mas especialmente por meio da justaposição da contradição entre os diversos imaginários que se fazem presentes e se relacionam harmoniosamente com nosso cotidiano, corroborando com aquilo que Filipe Furtado chama de "o falso verossímil" (FURTADO, 1980, p.44). Como procuramos mostrar, "a utilização do maravilhoso na narrativa, embora indispensável ao fantástico, não é de forma alguma fator exclusivo dele" (FURTADO, 1980, p.15).

Com base na fecunda historiografia cultural e nas teorias literárias do fantástico, reconhecemos que as diversas instâncias do imaginário fantástico, da dionisíaca loucura ao fanatismo religioso, ganham força em muitas realidades vividas, principalmente nas sociedades pré-industriais. Com isso, devemos notar a possibilidade interpretativa que há no cruzamento da Relação de Âlvaro Velho com a Peregrinação de Barnabé das Índias, principalmente por meio do preenchimento imaginário de uma grande zona obscura, existente na fonte histórica que registrou essa viagem portuguesa de 1497 .

Isso pois, diante das imagens documentais dessa viagem, resumidas com esplendor em seu poderio militar e com cientificidade na exposição de novos cálculos e práticas de navegação, o que temos é um verdadeiro silêncio sobre as fraquezas físicas e psicológicas da tripulação e, também, sobre os pontos de vista das comunidades orientais que receberam os portugueses em suas terras. É possível afirmar que essas ausências justificam literária e historicamente a importante presença do maravilhoso na representação romanesca de Vasco da Gama e sua tripulação errante.

Nessa zona obscura, portanto, é que o escritor português encontra o seu campo de trabalho. Na falta de dados concretos sobre os imaginários que cercaram tal viagem, recorre-se à contextualização e, principalmente, aos pensamentos e às crenças historicamente possíveis daquela época. Ao não encontrar as características de que estava à procura na documentação disponível, o romancista português se voltou, na medida do possível, para outras fontes do mesmo tempo e do mesmo lugar, a fim de descobrir o mundo subjetivo em que Vasco e sua tripulação viviam e as reações que podem ter tido antes, durante e depois do primeiro périplo africano. Se o que o escritor oferece é, em parte, uma espécie de invenção, está, no entanto, solidamente arraigada nas vozes e nos valores do passado representado.

A arte de ler os rastros fornecidos pelas matérias subjetivas das fontes históricas, e inscrever os delírios que muitas vezes destorcem a imagem 
épica propagada pela tradição fazem parte de um movimento de se apoderar das narrativas caladas e apagadas. A arte calcada no significante, marcado pelo silêncio, volta-se para sua tarefa de salvar os fragmentos ou aquilo que não foi explicitamente revelado no registro de uma época ou de um evento histórico. Nesse tipo de arte

persiste a indiferenciação entre ficção, falsificação, ilusão e realidade, mas ela tem um compromisso com a verdade, por mais subjetivado que esse conceito apareça. Essa arte não se submete sem mais ao lema, típico da modernidade, o verdadeiro engano está na promessa de autenticidade. A arte aposta em uma nova autenticidade, pós-metafísica, pós-positivista, mas engajada em elaborar, inscrever e denunciar a violência [das apropriações]. (SELIGMANN-SILVA, 2013, p. 42-43)

A partir dessas considerações, o que temos que ter em conta é que a narração de Mário Cláudio não é centrada "na contraposição entre verdadeiro e inventado, mas na integração, sempre assinalada, de realidade e possibilidades" de apropriação. (GINZBURG, 2007, p. 315). Para isso,

é preciso reconhecer que alguns livros de história têm uma estrutura mais narrativa do que outros. Porém, o que, em geral, é ressaltado não é o campo de conhecimento identificável nas narrações de ficção, por exemplo, nas narrativas romanescas, mas sim o nível fabulatório identificável nas narrações com pretensões científicas - a começar pelas narrativas historiográficas. A convergência entre os dois tipos de narração deve ser buscada no plano da arte, e não no da ciência. (GINZBURG, 2007, p. 326).

Por isso, devemos considerar o empreendimento historiográfico do romance em questão, ressaltando que a biografia dos personagens de Mário Cláudio se torna, de vez em quando, a biografia de outros homens do mesmo tempo e do mesmo lugar, reconstruída com sagacidade e paciência mediante fontes históricas, cartoriais e literárias associados ao evento histórico e seu contexto político-cultural'3. Com tal estratégia, observamos quea história dessa viagem foi reescrita por Mário Cláudio, nos fornecendo uma interpretação historicamente elaborada desse episódio

${ }^{13}$ “Termos como ficção ou possibilidade não devem induzir a erro. A questão da prova permanece mais que nunca no cerne da pesquisa histórica, mas seu estatuto é inevitavelmente modificado no momento em que são enfrentados temas diferentes em relação ao passado, com a ajuda de uma documentação que também é diferente." (GINZBURG, 2007, p. 334). 
constituído por diversas circunstâncias da vida corrente no Renascimento, em que os hábitos mentais e as formas fantásticas reaparecem vivamente.

Portanto, temos, nessa "narrativa historiográfica", as caóticas feiras e as romarias de Lamego à Belém, os prazeres, as visões e as mazelas de Vasco da Gama da infância à velhice. Indicam todos cenários de ampla representação do maravilhoso, seja ele no seu aspecto mais religioso ou no seu aspecto mais místico e mitológico. Exemplo histórico digno de complementar a existência dessa matéria imaginária na vida de Vasco é o caso da famosa casa pintada de Évora. Expulso de Sines, em obediência ao Rei, vai Vasco da Gama viver em Évora, em uma casa cuja frente mandou decorar com painéis que traziam representações imaginárias, florais e faunísticas inspirados na Índia, tendo, por isso, "a respectiva rua ficado conhecida nessa cidade por Rua das Casas Pintadas, designação posteriormente substituída por rua Vasco da Gama." (FERREIRA, 1998, p. 38).

Os painéis não sobreviveram como também grande parte da estrutura original da casa. Inclui-se, porém, no processo original que está na Sociedade de Geografia de Lisboa, o interessante documento em que "D. Manuel, estando ainda em Évora, em 17 de dezembro de 1519, faz a Vasco da Gama pura e irrevogável doação para todo o sempre do título de Conde da Vidigueira" (CORDEIRO, 1892, p. 25). Fica, com esse documento, definitivamente comprovada a existência da residência de Vasco da Gama em Évora, mas ainda relega-se a testemunhos orais do século XIX de que havia, decorativamente, na entrada da sua casa, pinturas fantásticas de alusão oriental.

De qualquer forma, aproveita Mário Cláudio toda a especulação histórica em torno dos motivos da pintura da casa de Vasco em Évora para preencher ficcionalmente a representação do famoso personagem histórico com tais imaginários:

[...] se exterioriza a ira da besta, pintada na parede do claustrim, obedecendo àquilo que ordenou ele que se executasse, [...]. E não sossega o monstro, e longamente o contempla o velho com seu jeito taciturno, [...]. Repentinamente se suspende aquela extrema turbação, e nem as neves que persistem em fustigar o Alentejo bastam a reprimir o grito que se expande na alma do que se encolhe de frio, [...]. (CLÁUDIO, 1998, pp. 21-22).

A hidra irada pintada na parede do quarto de Vasco é a representação de um micromundo imaginariamente harmônico e ordenado, que põe em evidência sua incapacidade de pensar a diversidade do planeta, 
apresentando o Almirante uma visão enraizada da qual não consegue se desfazer. O monstro é para Vasco da Gama efeito simbólico da totalização de seu mundo.

O imaginário opressor constituído de lendas foi uma forma instigante e produtiva que o autor do romance encontrou para explorar não só as lacunas históricas desse tema, mas também para explorar a cultura portuguesa em estado de crise, pois é isso que parecia dominar Portugal nos últimos anos do século XX, momento inundado pelas muitas formas literárias de representar a alienação dos portugueses perante sua própria história, formas a partir das quais Mário Cláudio escreveu sua obra.

A representação literária de um "irrealismo cultural” (REAL, 2012, p. 91) em algumas obras literárias resulta em uma provocante alegoria de efeito irônico, impregnada de misticismo e religiosidade para narrar e descrever o país. Seu conteúdo representativo evidencia criticamente "uma sociedade bloqueada, que vive quase exclusivamente de preconceitos e ilusões sociais, [...].” (REAL, 2001, p. 19).

É através dessa linha representativa que Mário Cláudio revê a época das navegações portuguesas, explorando os impactos da história na sociedade portuguesa ao elaborar uma imaginária versão para a viagem inaugural do caminho marítimo das Índias:

E percorrendo estes devaneios dilatados minutos, neles compreendi que não equivalia a avistada de bordo à minha povoação de fantasia, porque a que lhe ia botando eu [Vasco da Gama] em cima em nada se comparava à que realmente existia, em conseqüência de jamais vislumbrarmos no que se nos depara a completa verdade para que propendemos, seja ela agradável ou nefasta, mas uma envergadura onde os sonhos se cruzam com os desejos, e os torpores se misturam com os júbilos, e tão vulgar se faz este jogo que nele nem atentam os que o executam, e cada região achada em região dissipada se converte, e cada viagem em nova decepção, e se considerarmos que para o lado de lá se nos não antolha esplendor ou triunfo, antes morte da visão que da autêntica Cidade se separou, deduziremos que não significará a imaginada senão um engano do olhar. (CLÁUDIO, 1998, p. 208-209).

Os desvios oníricos da viagem, que refletem o mais puro sofrimento desses peregrinos, são causados pelo fato de não haver na história o estabelecimento coletivo de uma tomada de consciência relativa ao olhar que direcionam os tripulantes ao mundo oriental. A recorrência do verbo "antolhar" no romance serve para transfigurar a ação dos tripulantes mediante um limite cognitivo imposto pela tradição imaginária a respeito das terras e dos povos do Oriente. No trecho acima, retirado do capítulo 
As Cidades, apresenta-se Vasco da Gama desiludido - e ao mesmo tempo encantado - na sua primeira mirada a Calicute, cidade rica em especiarias de todo trato e que tanto desejavam descobrir os portugueses.

A vitalidade do maravilhoso na cultura da Baixa Idade Média e do Renascimento é incontestável, e seu processo de manifestação pode ser verificado também em bestiários, fisiólogos, mapas e epístolas dessa época histórica de complexa transição cultural. Todavia, é necessário ressaltar que o registro de elementos maravilhosos em muitas relações de viagens ultramarinas não se deu sob a base de um maravilhoso radical como ocorrera explicitamente naquelas fontes e em muitos relatos de viajantes medievais, em que se apresenta uma narrativa recheada de monstros e outros estranhamentos que revelavam a noção cristã medieval de mundo. Isso não quer dizer, todavia, que esse tipo de manifestação fantástica não estivesse presente na mentalidade das épocas posteriores e, especificamente, na mentalidade da tripulação de Vasco da Gama ${ }^{14}$.

De fato, é preciso considerar o acréscimo da experiência in loco dos viajantes modernos no território dos novos mundos que observam e representam. Mas nem por isso os relatos ultramarinos devem ser considerados como a mais pura ou a mais próxima representação da realidade oriental. Vemos com Sérgio Buarque de Holanda (1902-1982), em Visões do Paraíso (1959), as formas pelas quais os elementos físicos da natureza se incorporavam ao fantástico durante o Quinhentismo, pois, nessa época, o real ainda não era notado com espírito crítico suficiente, devido à força ainda latente da tradição.

A tese de Sérgio Buarque sobre as "atenuações plausíveis" consiste na explicação de que a fantasia permanecera no processo colonizador lusitano porque persistiu nesse processo o sonho de riquezas fabulosas por parte dos navegadores. Argumenta o estudioso brasileiro que o sonho de eldorados era cercado por uma noção mais nítida, ou melhor, mais plausível em relação à realidade terrena observada, como um maravilhoso de ordem física e quantitativa que ainda era verossímil aos navegantes: "Os velhos motivos edênicos vinham, portanto, a sobrepujar,

${ }^{14}$ Em uma primeira acepção, o maravilhoso preserva, assim, algo de humano, em sua essência. "A extraordinariedade se constitui da freqüência ou densidade com que os fatos ou os objetos exorbitam as leis físicas e as normas humanas. Em sua segunda acepção, o maravilhoso difere radicalmente do humano: é tudo o que é produzido pela intervenção dos seres sobrenaturais." (CHIAMPI, 2008, p. 49). 
no deslumbramento desses navegantes, a expressão de uma sensibilidade mais ligada ao real" (HOLANDA, 2010, p. 223).

Considerando essas "atenuações plausíveis", é preciso frisar que aspectos falsamente verossímeis parecem estar efetivamente explícitos na Relação de Álvaro Velho, através da exposição das lendas ultraterrestres, como vimos na primeira parte desse trabalho investigativo. Tal exposição fantasista tem como base a imagem mítica do reino de Preste João e outros reinos cristãos lendários, deixando de lado as imagens imaginárias mais insólitas. Porém, isso não quer dizer que os imaginários menos "plausíveis" não se fizessem presentes na mentalidade de Álvaro Velho e de toda a tripulação, pois, já dizia Ginzburg, a ausência de certos aspectos no documento histórico pode tornar-se um importante indício de sua manifestação, tornando necessária a busca pelas marcas de seu silenciamento.

Em sintonia com esse método indiciário, das três viagens históricas que Vasco da Gama realizou à Îndia, a primeira, a qual registrara Álvaro Velho, é, sem dúvida, a mais problemática e complexa em termos de representação imaginária, pois, segundo um interessante trecho do Tratado dos Gama (1599), do historiador Diogo do Couto, há nela uma intensa carga mítica pela temeridade e pelo espanto da viagem por rotas e terras desconhecidas, fatores que contribuíram para configurar a viagem mais como "cousa que hia para outro mundo", recebida com grande espanto por todos ao "verem hir aquellas naos, como os argonautas em busca do velocino de ouro, indo pera partes tão remotas e de que nimguem tinha notícia [...]." (COUTO, 1998, p. 35).

Isso explica, em parte, a relação que estamos traçando entre o relato de viagem de Álvaro Velho e o romance de Mário Cláudio, que pode ser justificada pela afirmação de muitos historiadores que dizem que os prodígios eos bestiários medievais, mesmo com oacréscimo da experiência do espaço oriental a partir do século XV, ainda vão ter um papel muito importante no plano explicativo das realidades observadas. "Nenhum dos mitos que retratavam outras partes do planeta era considerado impossível e mesmo no final desse século assiste-se ao nascimento de conjecturas quase tão espantosas para nós quanto às da Idade Média mais remota" (PINTO, 1989, p. 10).

Baseando-se nesse imaginário ocidental sobre o Oriente, a representação da viagem que encontramos no romance de Mário Cláudio é uma versão renovadora na perspectiva histórico-cultural, pois os fatos 
do passado são relidos e recriados em função de uma disposição crítica do investigador que narra tal episódio realçando cautelosamente os imaginários delirantes como forma de desconstruir o tom épico adotado pelas fontes históricas, não deixando de revelar por isso uma densa ligação com o documento histórico, tomando-o como fonte exclusiva de análise, desconstrução e criatividade.

Constatamos, ainda, que a originalidade do romance em questão consiste justamente no fato de que o escritor não reduz a viagem histórica de Vasco da Gama a uma representação abstrata ao se limitar em registrar seus possíveis imaginários. Concordamos com a leitura de que Mário Cláudio não é dualista, não pretende opor a realidade à aparência, como faz, em desespero de causa, o racionalismo recalcado. O romancista, ao contrário, afasta as banalidades tranquilizadoras, os objetos naturais em seu horizonte de prometedora racionalidade, a fim de devolver à realidade representada, a nossa originalidade irracional tão inquietante, histórica e, sobretudo, sociológica.

\section{REFERÊNCIAS BIBLIOGRÁFICAS}

ARAGÃO, Augusto Carlos Teixeira de. Vasco da Gama e a Vidigueira. In: Boletim da Sociedade de Geografia de Lisboa. Lisboa: Imprensa Nacional, 1886.

BAENA, Visconde de Sanches de. O Descobridor do Brazil, Pedro Álvares Cabral. Lisboa: Sociedade de Geografia de Lisboa, 1897.

BARRETO, Luís Filipe. Descobrimentos e Renascimento: formas de ser e pensar nos séculos XV e XVI. Lisboa: INCM, 1983.

BESSIÈRE, Irène. Le récit fantastique: La poétique de l'incertain. «thèmes et textes». Paris: Larousse, 1973.

CASTANHEDA, Fernão Lopes de. História do Descobrimento e Conquista da India pelos Portugueses. Lisboa: Officina de Simão Thaddeo Ferreira, 1797. Texto digitalizado e disponível em www.purl.pt. Acessado em 01/07/2014.

CESARANI, Remo. O fantástico. Curitiba: Editora da UFPR, 2006.

CHARTIER, Roger. A História Cultural entre práticas e representações. Rio de Janeiro/ Lisboa: Bertrand/Difel, 1990.

CHIAMPI, Irlemar. O Realismo Maravilhoso. 2ª Ed. São Paulo: Perspectiva, 2008. 
CIDADE, Hernani. A Literatura Portuguesa e a Expansão Ultramarina (séculos XV e XVI). 2à. Edição. Coimbra: Armênio Amado Editor, 1963, vol. 1.

CLÁUDIO, Mário. Peregrinação de Barnabé das Índias: Romance. Lisboa: Publicações Dom Quixote, 1998.

CORDEIRO, Luciano. Descobertas e Descobridores - De como e quando foi feito conde Vasco da Gama (Memória apresentada a 10. essão do Congresso Internacional dos Orientalistas). In: Boletim da Sociedade de Geographia de Lisboa. Lisboa: Imprensa Nacional, 1892.

COUTO, Diogo do. Tratado dos Feitos de Vasco da Gama e de seus filhos na Índia (1599). Introdução, leitura e glossário de José Manuel Azevedo e Silva e João Marinho dos Santos. Lisboa: Edições Cosmos, 1998.

CRUZ, António. O Porto nas navegações e na expansão. 2. a edição. Lisboa: Instituto de Cultura e Língua Portuguesa, 1983.

DIAS, José Sebastião da Silva. Os descobrimentos e a problemática cultural do século XVI. Lisboa: Editorial Presença, 1982.

DISNEY, Anthony. A Expansão Portuguesa (1400-180o): Contatos, Negociações, Interações. In: CURTO, Diogo Ramada; BETHENCOURT, Francisco. A Expansão Marítima Portuguesa (1400-180o). Tradução de Miguel Mata. Lisboa: Edições 70, 2010, pp. 295326.

FERREIRA, Maria Ema Tarracha. Vasco da Gama na literatura dos Descobrimentos. Lisboa: Biblioteca de Autores Portugueses, 1998.

FONSECA, Luís Adão da. Vasco da Gama. O homem, a viagem, a época. Lisboa: Vega, 1998.

FURTADO, Filipe. A construção do fantástico na narrativa. Lisboa: Livros Horizonte, 1980.

GINZBURG, Carlo. O fio e os rastros: verdadeiro, falso, fictício. Tradução de Rosa Freire d’Aguiar e Eduardo Brandão. São Paulo: Companhia das Letras, 2007.

GODINHO, Vitorino Magalhães. A Expansão Quatrocentista Portuguesa. 2. edição. Lisboa: Dom Quixote, 2008.

HOLANDA, Sérgio Buarque de. Visão do Paraíso. Os motivos edénicos no descobrimento e colonização do Brasil. São Paulo: Companhia das Letras, 2010.

MACHADO, Álvaro Manuel. Dicionário de Literatura Portuguesa. Lisboa: Editorial Presença, 1996.

MACHADO, Diogo Barbosa. Bibliotheca Lusitana historia, critica e cronológica. Lisboa: António Isidoro da Fonseca, 1752. Arquivo digitalizado disponível em www.purl.pt. Acessado em 01/o7/2014. 
MONTEIRO, José Sousa Monteiro. Vasco da Gama (A psychologia d'um heroe). In: Revista Portugueza Colonial e Maritima. Lisboa: Livraria Ferin, 1898, Vol. 2.

NORA, Pierre. Entre memória e história. A problemática dos lugares. In: Projeto História 10. Tradução de Yara Aun Khoury. São Paulo: Revista do Departamento de História da PUC/SP, Dezembro de 1993, no. 10, pp. 7-28.

ORLANDI, Eni Puccinelli. Terra à vista - Discurso do confronto: Velho e Novo Mundo. $2^{\underline{a}}$ ed. Campinas: Editora da Unicamp, 2008.

PINTO, João Rocha. A Viagem, Memória e Espaço - A Literatura Portuguesa de Viagens: os primitivos relatos de viagem ao Índico (1497-1550). In: Cadernos de História Económica e Social. Lisboa: Livraria Sá da Costa Editora, 1989, ํo 11-12.

PINTO, João Rocha \& COSTA, Leonor Freire. Relação anônima da segunda viagem de Vasco da Gama à Índia. In: Cidadania e História. Em homenagem a Jaime Cortesão (Cadernos da Revista de História Económica e Social, 6-7). Lisboa: Livraria Sá da Costa, 1985, pp. 141-199.

REAL, Miguel. Geração de 9o: romance e sociedade no Portugal contemporâneo. Porto: Campo das Letras, 2001.

REAL, Miguel. O Romance Português Contemporâneo. Alfragide: Editorial Caminho, 2012.

RICOEUR, Paul. A memória, a história, o esquecimento. Tradução de Alain François. Campinas: Editora Unicamp, 2008.

SELIGMANN-SILVA, Márcio. Fiç̧ão e imagem, verdade e história: sobre a poética dos rastros. In: Dimensões. Espírito Santo, vol. 30, 2013, pp. 17-51.

TODOROV, Tzvetan. Introdução à literatura fantástica. Tradução de Maria Ondina Braga. Lisboa: Moraes Editores, 1977.

VELHO, Álvaro. Roteiro da Viagem de Vasco da Gama. 2ª edição. Organizado por Alexandre Herculano e o Barão do Castello de Paiva. Lisboa: Imprensa Nacional, 1861. Versão digitalizada disponível em http://www.brasiliana.usp.br/. Acessado em 30/o6/2014

VELHO, Álvaro. Roteiro da viagem que em descobrimento da India pelo Cabo da Boa Esperança fez Dom Vasco da Gama em 1497. Publicado por Diogo Kopke e pelo Dr. Antonio da Costa Paiva. Porto: Typographia Commercial Portuense, 1838. Versão digitalizada disponível em www.archive.org. Acessado em 20/06/2014. 